\title{
The role of nursing in health care
}

\author{
Judith Shamian' \\ I RN, PhD, D.Sc, (Hon), LLD (Hon), FAAN, President - International Council of Nurses
}

Posing the question "what is the role of nursing in health care?" might sound like a ridiculous question to many. Some people will just dismiss the question, and say the role of nursing is central to health care, while others might say: what do you mean? The role of nursing is to care. Even others will have additional answers.

For me, the question is fundamental and the answer to the question will define for me what the profession is about, the structure and focus of our education system, of the research foci, and the practice and roles we as nurses should play in civil society.

First, I would reframe the question and drop the word "CARE" and ask the question "What is the Role of Nursing in Health?". Our health status is determined by many factors and only $25 \%$ of it is related to the "health care system". The remaining $75 \%$ is associated with Social Determinants of Health such as education, housing, employment and more. So, if asked; does "nursing have a role in health?", in my opinion the answer is YES.

ICN defines nursing as "Nursing encompasses autonomous and collaborative care of individuals of all ages, families, groups and communities, sick or well and in all settings. Nursing includes the promotion of health, prevention of illness, and the care of ill, disabled and dying people. Advocacy, promotion of a safe environment, research, participation in shaping health policy and in patient and health systems management, and education are also key nursing roles"(1).

If you look at another definition for example the definition by the American Nurses Association (ANA) they define nursing as "the protection, promotion, and optimization of health and abilities, prevention of illness and injury, alleviation of suffering through the diagnosis and treatment of human response, and advocacy in the care of individuals, families, communities, and populations"(2).

If you are to analyze carefully these and other definitions of nursing you will find some similarities i.e., the care of individuals and some differences i.e., inclusion of research in the ICN definition and inclusion of populations in the ANA definition.

While we have a general agreement of what nursing is and the role in health and/or health care, it is clear that the definition of the profession is still evolving.

For me, as the $27^{\text {th }}$ President of ICN, I see the role of nursing in a very broad way. When I look at the global health challenges I encounter big, complex topics like: Universal Health Coverage (UHC); Non-communicable disease (NCDs); Emerging \& Re-emerging Infectious diseases: Ebola, Tuberculosis, Upper Respiratory Illness; Health Care Financing; Systems Integration; People-Centred Health Systems; Natural and man made disasters; Human Resources for Health, including workforce shortage, migration, task shifting and more.

So in looking at this list, lets ask again, "What is the Role of Nursing in Health (care)"? I clearly see roles for nursing in four spheres, or as I have been talking about recently; in four different "Bubbles": 1) The Nursing Bubble; 2) The Health Care Bubble; 3) The Regional/National Bubble; 4) The Global Bubble

The role of nursing is essential in each and every one of these "Bubbles". Why do I think that nursing has a role in the "Global Bubble"? In the global bubble, we will find organizations like: the World Health Organization, the World Bank, International Labour Organizations, United Nations Populations Fund (UNFPA) and many more. These organizations all have mandates that are directly linked to health. For example one would consider the World Bank as a Bank and wonder what is its role in Health. In reality is that the World Bank is one of the biggest lenders and investors in health care system, in poverty eradication, in building economies, and more. As such both the "health", the "prosperity of the country", the "health care system", and subsequently the role of nursing will be significantly impacted by the actions and agreements that the World Bank will have with 
"Regional and National" governments, which reside in the $3^{\text {rd }}$ Bubble i.e., the Regional/National Bubble. The role of nursing in Bubbles one and two are usually understood by the nursing community.

The ICN Board, in its 2014 meeting, adopted a strategic plan for 2014-2018 that aims at closing the gap in the following key "Themes": Global voice; Strategic leadership; Policy impact; Diversification. For nursing to have the IMPACT on health that we have the knowledge, capacity and the desire to have, we need to consider the key themes of the ICN strategy. We need to find our "Voice"; it isn't sufficient to speak and publish in the "Nursing Bubble".

Others need to learn about the knowledge and contribution nursing can and does make to health. We need to commit to "Strategic Leadership"; it is difficult to believe how little presence we have around policy tables, even in the second bubble. Fewer and fewer nurses are to be found in the executive corridors of hospitals, governments, and international agencies. The numbers are shrinking and the leadership role, coupled with the voice, is fading away. As a result of this reality the "Policy Impact" of the nursing voice, knowledge and experience is minimal and we must turn the reality around. Global health will greatly benefit at the policy level if the nursing strategic leadership and global voice becomes more robust and have the presence it deserves, Nursing is a great force and a great value to society. We need to make sure that barriers are removed and we contribute to the health of our nations. We can do it by: strengthening nursing's influence; teaching policy courses and socialize graduate students to do placements outside of the nursing Bubble; moving outside the Nursing Bubble and sharing nursing's knowledge and expertise with the rest of the world; make an impact on the other Bubbles: at the local, national and international levels: using evidence to improve care and strengthen our position; ensuring our voices are heard; striving to become stronger leaders and lead our communities, our nations, and our populations to better health.

Our impact can be tremendous if we take upon ourselves to be the voice and the influence we need to be. We can have the impact we should have.

\section{REFERENCES}

1. International Council of Nurses. Definition of Nursing. 2014 http://www.icn.ch/about-icn/icn-definition-of-nursing/.

2. American Nursing Association. What is nursing? http://www.nursingworld.org/EspeciallyForYou/What-is-Nursing . 